\title{
Experimental Results for SimFuels
}

\section{Used Fuel Disposition}

Prepared for

U.S. Department of Energy Separations/Waste Form Campaign E. C. Buck, A. M. Casella, F. N. Skomurski-Smith, P. J. MacFarlan, C. Z. Soderquist, R. S. Wittman, B. K. McNamara

Pacific Northwest National Laboratory August, 2012

FCRD-UFD-2012-000247

PNNL-21646 


\section{DISCLAIMER}

This information was prepared as an account of work sponsored by an agency of the U.S. Government. Neither the U.S. Government nor any agency thereof, nor any of their employees, makes any warranty, expressed or implied, or assumes any legal liability or responsibility for the accuracy, completeness, or usefulness, of any information, apparatus, product, or process disclosed, or represents that its use would not infringe privately owned rights. References herein to any specific commercial product, process, or service by trade name, trade mark, manufacturer, or otherwise, does not necessarily constitute or imply its endorsement, recommendation, or favoring by the U.S. Government or any agency thereof. The views and opinions of authors expressed herein do not necessarily state or reflect those of the U.S. Government or any agency thereof. 


\section{SUMMARY}

This report satisfies the Used Fuel Disposition M3 Milestone, Experimental Results for SimFuels, (M4FT-12PN0806053).

Assessing the performance of Spent (or Used) Nuclear Fuel (UNF) in geological repository requires quantification of time-dependent phenomena that may influence its behavior on a time-scale up to millions of years. A high-level waste repository environment will be a dynamic redox system because of the time-dependent generation of radiolytic oxidants and reductants and the corrosion of Fe-bearing canister materials (Carbol et al. 2009). One major difference between used fuel and natural analogues, including unirradiated $\mathrm{UO}_{2}$, is the intense radiolytic field. The radiation emitted by used fuel can produce radiolysis products in the presence of water vapor or a thin-film of water that may increase the waste form degradation rate and change radionuclide behavior.

To study UNF, we have been working on producing synthetic $\mathrm{UO}_{2}$ ceramics, or SimFuels that can be used in testing and which will contain specific radionuclides or non-radioactive analogs so that we can test the impact of radiolysis on fuel corrosion without using actual UNF. Although, testing actual UNF would be ideal for understanding the long term behavior, it requires the use of hot cells and can be extremely expensive. In this report we discuss factors influencing the preparation of SimFuels and the requirements for dopants to mimic the behavior of UNF. We have developed a reliable procedure for producing large-grain $\mathrm{UO}_{2}$ at moderate temperatures. This process will be applied to a series of different formulations.

As part of the effort to model the radiolysis environment, we are also conducting tests on radioactive systems and examining the formation of hydrogen peroxide $\left(\mathrm{H}_{2} \mathrm{O}_{2}\right)$ which is the dominant oxidant for spent nuclear fuel in an $\mathrm{O}_{2}$-depleted water environment (Sunder et al. 1997, Pastina and LaVerne, 2001, Roth and LaVerne, 2011), and based on modeling work reported earlier (see Buck et al., 2012). The reliable and accurate measurement of $\mathrm{H}_{2} \mathrm{O}_{2}$ at low levels has been the focus of this year's work. This methodology will enable us to perform radiolysis experiments under various conditions and model the most sensitive parameter with respect to predictions of the radiolysis model. The direct measurement of $\mathrm{H}_{2} \mathrm{O}_{2}$ is not straightforward as complexing agents that are used to measure $\mathrm{H}_{2} \mathrm{O}_{2}$ may impact the system under investigation (Pastina and LaVerne, 2001, Sunil and Narayana, 2008). We have experimented with several methods for detecting $\mathrm{H}_{2} \mathrm{O}_{2}$ with the aim of reducing detection levels as far as possible. We have

found that using a long-path length analyzer we can detect to $10^{-7} \mathrm{M} \mathrm{H}_{2} \mathrm{O}_{2}$ using a Ti(IV)OSO $\mathrm{OS}_{4}$ solution as the indicator. 


\section{CONTENTS}

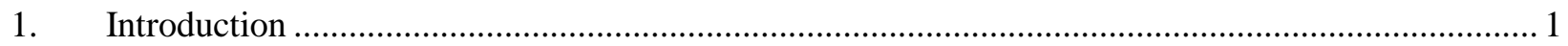

1.1 Solid Solubility of Dopants in Uranium Oxide ............................................................. 1

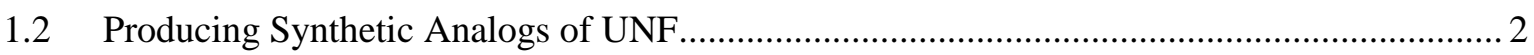

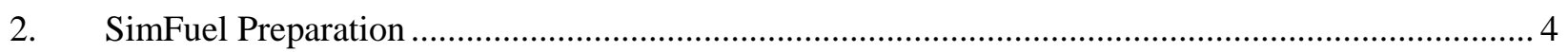

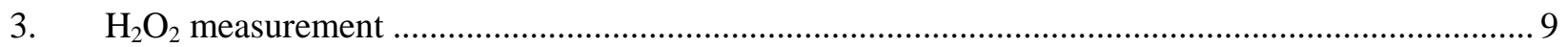

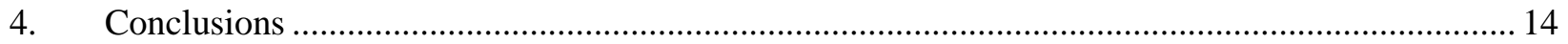

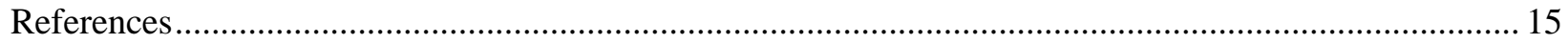

\section{FIGURES}

Figure $2.1 \mathrm{UO}_{2+\mathrm{x}}$ Sintered in Neon at $1400^{\circ} \mathrm{C}$ for 24 hours, pressed at 6000 pounds in an $11.5 \mathrm{~mm}$ die

Figure 2.2 Low magnification SEM image of $\mathrm{UO}_{2+\mathrm{x}}$ Sintered in Neon at $1400^{\circ} \mathrm{C}$ for 24 hours, pressed at 6000 pounds in an $11.5 \mathrm{~mm}$ die

Figure 2.3 Medium Magnification SEM image of $\mathrm{UO}_{2+\mathrm{x}}$ Sintered in Neon at $1400^{\circ} \mathrm{C}$ for 24 hours,

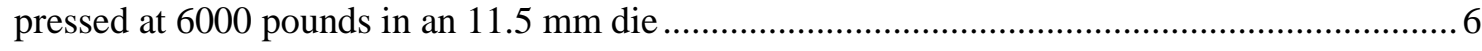

Figure 2.4 SEM image of $\mathrm{UO}_{2+\mathrm{x}}$ Sintered in Neon at $1400^{\circ} \mathrm{C}$ showing grain structure ............................. 7

Figure 2.5 SEM image of $\mathrm{UO}_{2+\mathrm{x}}$ Sintered in Neon at $1400^{\circ} \mathrm{C}$ showing the presence of unsintered

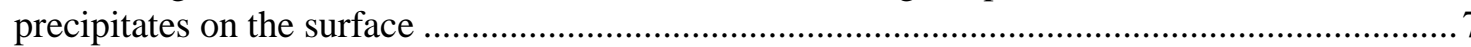

Figure 3.1 Photograph of a series of $\mathrm{H}_{2} \mathrm{O}_{2}$ concentrations using Ti(IV)OSO $\mathrm{OS}_{4}$ as the indicator................. 9

Figure 3.2 Short path length UV-Vis spectra for $\mathrm{H}_{2} \mathrm{O}_{2}+\mathrm{Ti}(\mathrm{IV}) \mathrm{OSO}_{4}$ as indicator showing detection upwards of $7 \times 10^{-6} \mathrm{M}$ (background subtracted).

Figure 3.3 Calibration plot for the detection of $\mathrm{H}_{2} \mathrm{O}_{2}$ with Ti(IV)OSO $\mathrm{OS}_{4}$ indicator: (a) $1 \times 10^{-7} \mathrm{M}$ to $1 \times 10^{-3} \mathrm{M}$ and (b) $1 \times 10^{-4}$ and lower

Figure 3.4 Averaged UV-Vis data for methylene blue indicator.

Figure 3.5 Comparison of new and old peroxide samples with different batches of $\mathrm{Ti}(\mathrm{IV}) \mathrm{OSO}_{4}$ as the indicator.

Figure 3.6 Long path-length UV-Vis for $\mathrm{H}_{2} \mathrm{O}_{2}+\mathrm{Ti}(\mathrm{IV}) \mathrm{OSO}_{4}$ as indicator.. 


\section{ACRONYMS}

PNNL Pacific Northwest National Laboratory

$\mathrm{MWd} / \mathrm{t} \quad$ Mega-Watt days per metric Tonne of $\mathrm{UO}_{2}$ fuel

SEM Scanning Electron Microscopy

UFD Used fuel disposition

UNF Used nuclear fuel

UV-Vis ultra-violet-visible light 


\section{Introduction}

Assessing the performance of Spent (or Used) Nuclear Fuel (UNF) in geological repository requires quantification of time-dependent phenomena that may influence its behavior on a time-scale up to millions of years. A high-level waste repository environment will be a dynamic redox system because of the time-dependent generation of radiolytic oxidants and reductants and the corrosion of Fe-bearing canister materials (Stroes-Gascoyne et al. 2005, Carbol et al. 2009). One major difference between used fuel and natural analogues, including unirradiated $\mathrm{UO}_{2}$, is the intense radiolytic field. The radiation emitted by used fuel can produce radiolysis products in the presence of water vapor or a thin-film of water that may increase the waste form degradation rate and change radionuclide behavior. To study this process and to determine the disposition of radionuclides, we have embarked on preparing synthetic $\mathrm{UO}_{2}$ fuels with various dopants. Producing doped- $\mathrm{UO}_{2}$ ceramics suitable for testing requires control of the preparation conditions and understanding of the solid solubility of specific elements of interest.

\subsection{Solid Solubility of Dopants in Uranium Oxide}

Uranium dioxide is known to accommodate various metals ions (M) forming substitutional solid solution of the type $\mathrm{M}_{\mathrm{y}} \mathrm{U}_{1-\mathrm{y}} \mathrm{O}_{2+\mathrm{x}}$. Dopants may change the thermodynamic, chemical, and transport properties of oxide fuel. In this study, we were interested in using specific dopants to replace specific radionuclides so that we can address particular issues regarding long-term stability. Uranium dioxide crystallizes into the fluorite structure $\left(\mathrm{CaF}_{2}\right)$ with $\mathbf{a}=0.547 \mathrm{~nm}$ and belongs to the $F m 3 m$ space group. The lattice can be described as an $f c c$ cation lattice where all the tetrahedral sites are occupied by an oxygen atom. This leads to a cubic symmetry around each cation ( 8 oxygens at $0.237 \mathrm{~nm}$ ) (Willis, 1978). The radius of the $\mathrm{O}^{2-}$ ion in the lattice is $0.137 \mathrm{~nm}$ and the $\mathrm{U}^{4+}$ ion is $0.103 \mathrm{~nm}$. The process of solidification occurs by a mechanism of nucleation and growth, i.e. minute nuclei, or seed crystals are formed in various parts of the melt which then grow at the expense of the surrounding liquid until the whole volume is solid. Sintering of $\mathrm{UO}_{2}$ changes the microstructure progressively through a number of stages. In the first stage of sintering there is abundant open porosity, and then the total volume of pores decreases steadily. At $96 \%$ of theoretical density, open porosity is effectively eliminated; however, a number of inaccessible pores still exist in the material. The closed pores eventually shrink to the point that they no longer hinder the movement of dislocations. At this point the pores change from an irregular polyhedral shape to being orientated parallel to the lower energy crystallographic planes in the surrounding $\mathrm{UO}_{2}$ grain. The ionic constraints appear to dominate solid solubility limits of dopants ions into $\mathrm{UO}_{2}$; however, we can increase 
solubility limits through lattice relaxation mechanisms. Addition of smaller rare earths ions into $\mathrm{UO}_{2}$ can increase the solid solubility limits of larger ions (Une and Oguma, 1988, Harada, 1996).

During grain growth the liquid eutectic is swept along by the grain boundaries until the grains become sufficiently large and each grain boundary is delineated by eutectic. The fraction of grain boundary covered by eutectic depends on the volume of the eutectic. Densification and excess grain growth of $\mathrm{UO}_{2}$ can be attributed to the formation of liquid-phase eutectic between the dopant $\left(\mathrm{Nb}_{2} \mathrm{O}_{5}, \mathrm{TiO}_{2}\right.$ etc. $)$ and $\mathrm{UO}_{2}$ at the sintering temperatures. Grain growth rates are greatest with dopants that form simple eutectics with $\mathrm{UO}_{2}$ and/or have only partial solubility in $\mathrm{UO}_{2}$. Niobium, chromium, and titanium are known to cause this rapid increase in grain growth via the eutectic mechanism (Harada, 1996). Ainscough et al. (1974) determined that the rate of $\mathrm{UO}_{2}$ grain growth was proportional to the concentration of added $\mathrm{TiO}_{2}$ within the limits of solubility. It is also likely, however, that other elements are capable of producing similar effects. The volume of eutectic will depend on the oxide melting point and the degree of incompatibility of the dopant ion in $\mathrm{UO}_{2}$. Based on ionic radius considerations (60-75 pm) (Shannon, 1976) and oxide melting points $\left(>1800^{\circ} \mathrm{C}\right)$, the oxides of $\mathrm{Al}^{3+}, \mathrm{V}^{3+/ 4+}, \mathrm{Ta}^{3+/ 4+}, \mathrm{Ni}^{2+}, \mathrm{Ga}^{3+}, \mathrm{Sn}^{4+}, \mathrm{Co}^{2+}$, and $\mathrm{Fe}^{3+}$, are predicted to induce rapid excess grain growth in $\mathrm{UO}_{2}$ crystals during reactive sintering. The exact sintering temperatures will vary and conditions for optimized grain growth would have to be established experimentally.

\subsection{Producing Synthetic Analogs of UNF}

Commercial $\mathrm{UO}_{2} \mathrm{LWR}$ fuels have small, uniform grain size. During reactor operation, the temperature at the centerline of the fuel pellets may be as high as $1700^{\circ} \mathrm{C}$ depending on the reactor design, operating conditions, and on the thermal conductivity of the fuel. The fuel is also exposed to an intense radiation field that can increase the mobility of the fission products (Kleykamp, 1985). The elevated temperature can cause restructuring of the $\mathrm{UO}_{2}$ grains and permit fission products that have a limited solid solubility in $\mathrm{UO}_{2}$ to segregate to gain boundaries. The extreme radiation field that $\mathrm{UNF}$ is exposed to during reactor operation results in the formation of numerous defects. These defects migrate at the high reactor operation temperatures resulting in the formation of various structures. These effects result in significant differences between UNF and SimFuels. We are interested in trying to duplicate the UNF condition as much as possible. For instance, one important difference is the, so called, Rim Effect.

The Rim Effect occurs because burn-up is not uniform across the pellet. It increases dramatically at the pellet rim. This effect may be detrimental to the lifetime of the fuel; although it is not clear what the impact this behavior would have for final disposal. During irradiation of the fuel, neutrons are absorbed by ${ }^{238} \mathrm{U}$ leading to production of ${ }^{239} \mathrm{Pu}$ in the fuel. At the pellet edge, the resonance energies for 
absorption tend to be optimized for ${ }^{239} \mathrm{Pu}$ production. The ${ }^{239} \mathrm{Pu}$ may undergo neutron capture or fission leading to a buildup of high actinides and fission products. Metallic particles in the rim region tend to have higher concentrations of palladium.

One consequence of the rim restructuring as compared to $\mathrm{UO}_{2}$, is the reduction in thermal conductivity. The incorporation of fission products from the increased burn-up is known to decrease thermal conductivity significantly. This creates a heat barrier that can induce higher temperatures in the core of fuel pellets. In the rim region of a spent fuel, restructuring of the grains leads to a significant reduction in the grain size. Thomas et al. (1992), observed 0.02 to $1.0 \mu \mathrm{m}$ grains in the rim region of ATM106 (burnup was $\sim 45 \mathrm{MWd} / \mathrm{t}$ ). In the rim region of $78 \mathrm{MWd} / \mathrm{t}$ fuel, Ray et al. (1997) observed grains between 0.15 and $0.3 \mathrm{~mm}$ in diameter. Une et al. (1997) has suggested that the driving force for rim restructuring is radiation damage. However, as radiation damage will be extreme in all regions of the fuel pellet yet only the rim undergoes restructuring. This indicates that the lower temperatures in the rim may be responsible for reducing self-annihilation of defects. Spino et al. (2000) also suggest that radiation damage cannot be the only driving mechanisms for polygonization, they have argued that the courser Xe bubbles in the rim induce strain leading to restructuring. 


\section{SimFuel Preparation}

Although the technology to fabricate sintered $\mathrm{UO}_{2}$ pellets has been well known for quite some time, there are several parameters that must be identified and controlled in order to produce pellets with the desired physical properties for use as nuclear fuels. These parameters must be understood and controlled to an even higher degree when the desired product is a sintered solid solution of dopants in $\mathrm{UO}_{2}$. Although several successful processes have been developed to produce the desired solid solutions with various degrees of densification, oxidation state, and grain size, these processes generally need significant modification when performed on a laboratory (small) scale as opposed to larger scale operations. Traditionally, the parameters to be concerned with are:

1. The initial condition of the $\mathrm{UO}_{2}$ and dopant materials - This is generally determined from the method used to generate the initial materials which can affect particle size, surface area, and density.

2. Mixing/Milling-_Generally, the $\mathrm{UO}_{2}$ powder is milled to minimize particle size and maximize surface area. For some milling technologies, such as a ball mill, dopants can be milled at the same time as the $\mathrm{UO}_{2}$ and mixing of the dopants and the matrix can occur simultaneously.

3. Binders - Often binders are used to help maintain the integrity of green pellets prior to sintering. It is best to avoid binders if possible or to use minimum quantities of binders to reduce the possibility of contamination of the final product pellets. Also, the binders must be baked off during the sintering process and care must be taken to ease through the binder boiling point so as not to disrupt the physical integrity of the pellet. Additionally, the use of some binders has been demonstrated to affect the final sintered density of pellets. Binders are most effectively integrated into the pellet structure during the mixing/milling operation.

4. Pre-Compaction and Granulation - Typically the mixtures are pressed at a relatively low compaction pressure and then granulated by forcing the compacts through a sieve to produce granules that are roughly a millimeter in diameter. These granules are then pressed at a high compaction pressure to make the green pellets. This process is largely performed because the granulated powder is "flowable" and reliable quantities of the granulated powders can be evenly poured into dies used in large-scale fabrication facilities. The pre-compaction and granulation process also acts to evenly distribute the compaction load throughout the volume of the green pellet.

5. Sintering - Industrially, $\mathrm{UO}_{2}$ is sintered at $\sim 1750^{\circ} \mathrm{C}$ in a heavily reducing atmosphere $\left(\mathrm{H}_{2}\right)$. This drives the $\mathrm{UO}_{2}$ to a stoichiometric arrangement from the starting material in the green pellet of 
$\mathrm{UO}_{2+\mathrm{x}}$ where $\mathrm{x}$ is close to 0 . Various ramp rates, holds temperatures and hold times (sintering profiles) can be coupled with different sintering atmospheres to control the final pellet structure.

Our current objective has been to produce small batches ( $1-5$ grams) of sintered disks of urania doped with various compounds for research purposes. The fact that we were dealing with very small quantities of material dictated the manner in which we addressed each of the steps listed above. Firstly, to minimize any preparation necessary for the starting urania itself, we purchased $\mathrm{UO}_{2+\mathrm{x}}$ powder from a vendor that had been extracted from the industrial fabrication stream just prior to pre-compaction and was considered to be in "sinterable" form. This meant that no milling of the powder should have been necessary. However, milling of dopant materials was desirable to generate a homogeneous solid solution. Since most dopants are softer than urania, one method of mixing the dopants with the urania is to co-mill them in a ball mill prior to pre-compaction. However, if the dopants can be acquired in a well-milled form, it is desirable to mix the dopants with the urania. This avoided the relatively large fraction of material that was lost during the handling of small quantities of powder. The powder tended to stick to all surfaces that it came into contact with, including milling media, milling containers, and sieves. Although mixing by hand did not generate a highly homogenous mixture, there was still an opportunity to improve homogeneity during the sintering process. The diffusion of dopants within a $\mathrm{UO}_{2}$ matrix is very slow; however, this diffusion is greatly accelerated if $\mathrm{UO}_{2}$ is replaced with $\mathrm{UO}_{2+\mathrm{x}}$. If the oxidation state of the final sintered pellet is of little consequence, then a homogenous pellet can be generated by sintering $\mathrm{UO}_{2+\mathrm{x}}$ at lower temperatures $\left(\sim 1400^{\circ} \mathrm{C}\right)$ in an inert atmosphere. This process will also generate large grains in the final pellet. If the desired final product is $\mathrm{UO}_{2}$, then an initial heat soak at up to $900^{\circ} \mathrm{C}$ (personal communication with Dr. Lou Vance, Australian Nuclear Science and Technology Organization) in an oxidizing environment (such as air) can provide conditions for dopant diffusion within the pellet to encourage homogenization. This heat soak is then followed by high temperature sintering $\left(1400^{\circ} \mathrm{C}-\right.$ $\left.1750^{\circ} \mathrm{C}\right)$ in a reducing atmosphere to generate a well-mixed sintered pellet, but very small grain sizes $(\sim 1$ micrometer) often result.

The following attempts were made at manufacturing urania-based pellets for the project. One attempt included simply pressing the powder with 6000 pounds (lbs) of force in an $11.5 \mathrm{~mm}$ die $(\mathrm{d}=11.5 \mathrm{~mm}$, $\mathrm{A}=0.161 \mathrm{in}^{2}, \mathrm{P}=37,267 \mathrm{psi} ; 2570 \mathrm{bar} ; 257 \mathrm{MPa}$ ) and sintering in neon gas under the profile (see Figure $2.1)$ :

1. Ramp from room temperature to $370^{\circ} \mathrm{C}$ in 5 minutes

2. Hold at $370^{\circ} \mathrm{C}$ for 90 minutes

3. Ramp from $370^{\circ} \mathrm{C}$ to $1400^{\circ} \mathrm{C}$ in 206 minutes (ramp rate of $5^{\circ} \mathrm{C} / \mathrm{min}$ )

4. Hold at $1400^{\circ} \mathrm{C}$ for 24 hours 
5. Ramp from $1400^{\circ} \mathrm{C}$ to $370^{\circ} \mathrm{C}$ in 256 minutes (ramp rate of $4^{\circ} \mathrm{C} / \mathrm{min}$ )

6. Turn off furnace and let the temperature drop to room temperature without furnace control

This sintering profile was used to match several aspects of reportedly successful sintering profiles, but was limited by available equipment capabilities. The tube furnace used in this study was incapable of efficiently controlling the temperature at low temperatures, so the ramp rate was not highly controlled in this range. We did not exceed a sintering temperature of $1400^{\circ} \mathrm{C}$. Trying to reach higher temperatures or to control the temperature under $370^{\circ} \mathrm{C}$ has resulted in the breaking of furnace elements.

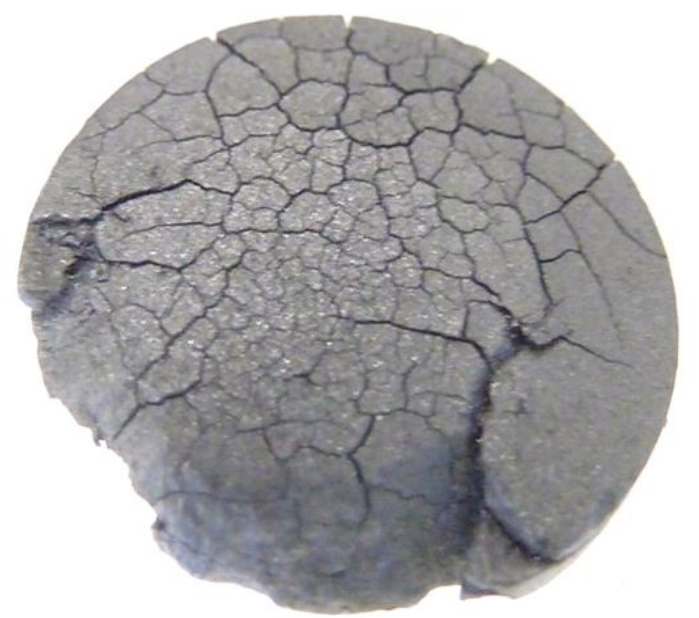

Figure $2.1 \mathrm{UO}_{2+\mathrm{x}}$ Sintered in Neon at $1400^{\circ} \mathrm{C}$ for 24 hours, pressed at 6000 pounds in an $11.5 \mathrm{~mm}$ die

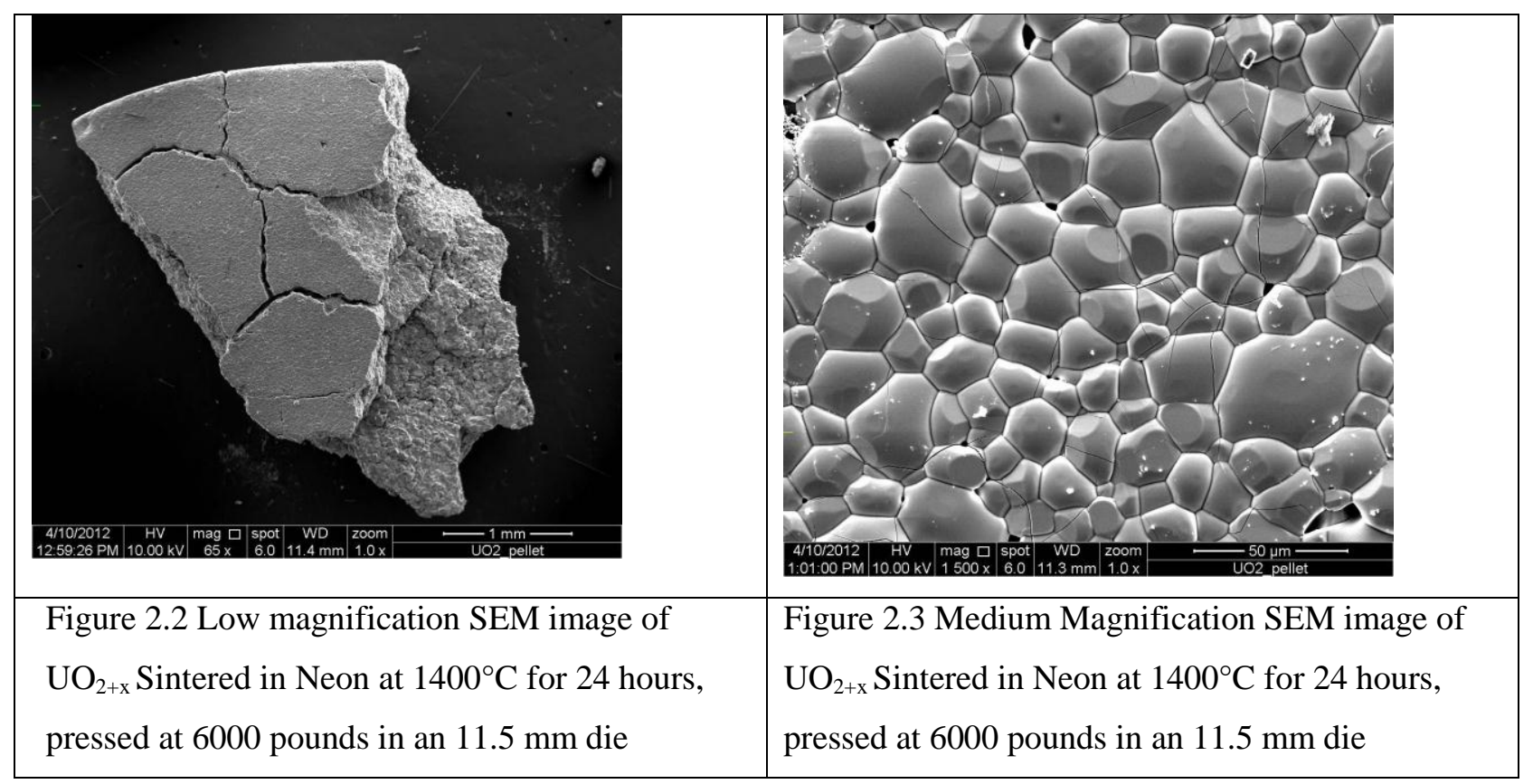




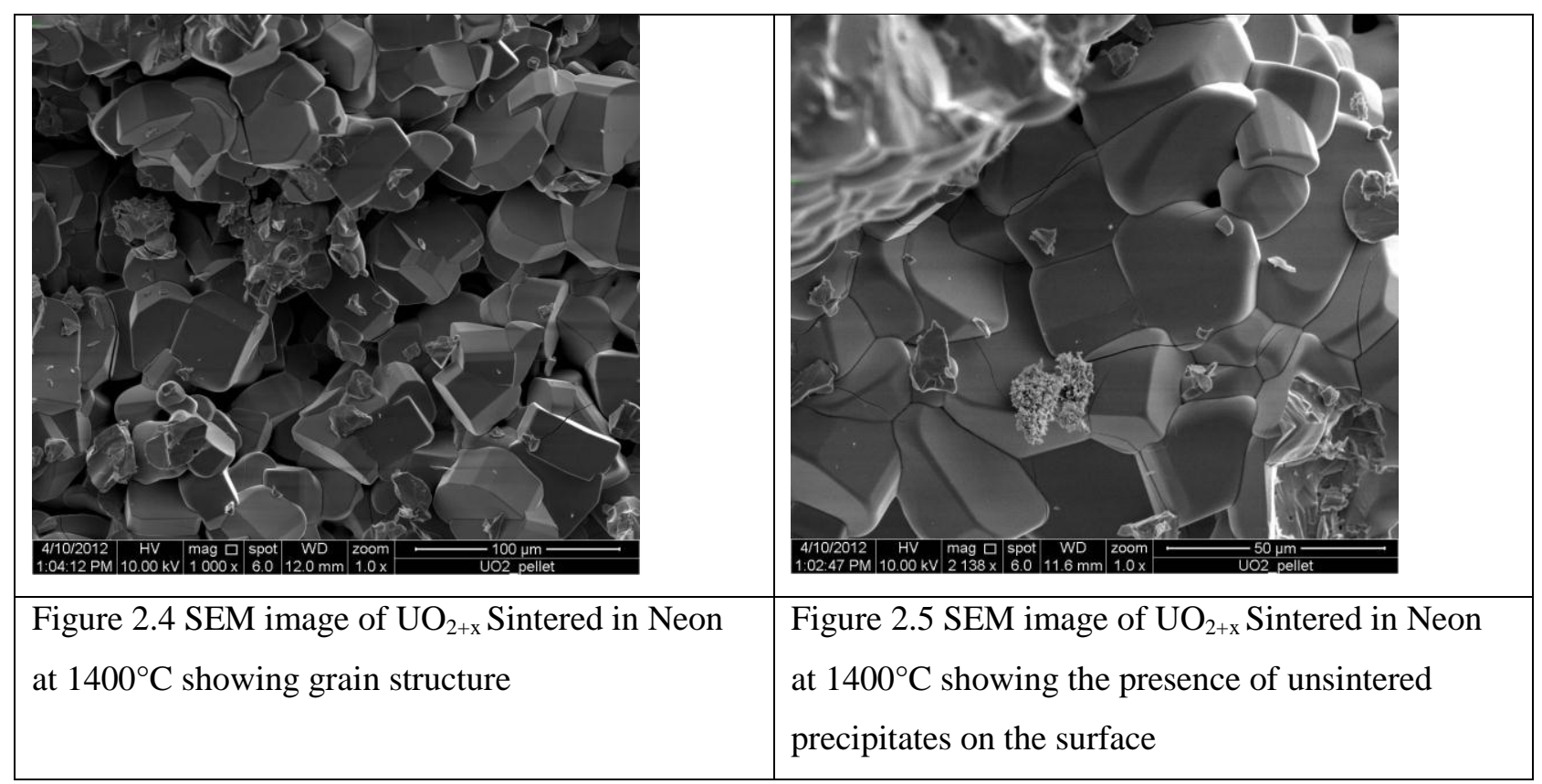

The pellet shown in Figure 2.2 through Figure 2.5 had the desired grain size and was thoroughly densified, but the large scale structure was not good. To maintain the desired characteristics of the pellet and to improve the undesired characteristics, it appeared that the pellet needed to be pressed to higher pressures. This was supported by the literature in which compaction pressures for green pellets are generally $3 \mathrm{kbar}$ (Vollath et al. 1982a), 130 - 500 MPa (Vollath et al. 1982b), 300 MPa (Kutty et al. 2002), and 267 MPa (Kim et al. 2002). These compaction pressures reported in the literature were for urania-based pellet fabrication studies that included sintering in various atmospheres. There was reason to believe that the pellet pressing that was used to generate the pellet shown in Figure 2.2 through Figure 2.5 was sufficient for making solid final pellets in a reducing sintering atmosphere. We were successful in that a pellet prepared in an identical way (but including a small percentage of $\mathrm{MoO}_{2}$ ) was properly sintered but was composed of grains that were very small $(\sim 1-2 \mu \mathrm{m})$.

To address the issue of pellet disintegration during sintering in an inert atmosphere, we pressed green pellets at higher pressures of 335, 419, and $503 \mathrm{MPa}$. These pellets were pressed in a $13 \mathrm{~mm}$ die in an attempt to distribute the load more efficiently (as granulation was not being performed). However, the pellet pressed at $503 \mathrm{MPa}$ disintegrated during ejection from the die and the pellet pressed at $335 \mathrm{MPa}$ disintegrated during measurement. The pellet pressed at $419 \mathrm{MPa}$ was not measured and remained intact. To avoid this issue of disintegration of the pellet, it was necessary to use a binder. In the reported literature the binders used have been $0.6 \mathrm{wt} \%$ zinc stearate (Vollath et al. 1982a; Vollath et al. 1982b), 1 wt\% zinc behenate (Kutty et al. 2002), or 0.22 wt\% zinc stearate, stearic acid, or Acrawax (Kim et al. 2002). It was reported that binders that include zinc leave a zinc residue that can reduce the sintered 
density of the pellet (Kim et al. 2002). Thus, it was decided to use stearic acid - first at a concentration of $1 \mathrm{wt} \%$.

We were also interested in forming $\mathrm{UO}_{2}$ ceramics in a $4 \% \mathrm{H}_{2} / \mathrm{N}_{2}$ atmosphere which led to a pellet that sintered much better; however, the grains were extremely small. To produce well-sized grains, typical of a fuel, we needed to sinter the $\mathrm{UO}_{2+\mathrm{x}}$ in $100 \% \mathrm{H}_{2}$ at $\sim 1725^{\circ} \mathrm{C}$. The value of $\mathrm{x}$ may be adjusted with a small quantity of water vapor in the sintering atmosphere which is how this is done in fuel fabrication plants. However, our furnace only functioned reliably at temperatures below $1400^{\circ} \mathrm{C}$. If we sintered in a reducing atmosphere (such as $4 \% \mathrm{H}_{2}$ in $\mathrm{N}_{2}$ ), then the pellets were of good quality but there was limited grain growth. The grain growth in $\mathrm{UO}_{2}$ does not proceed at an appreciable rate until $\sim 1700^{\circ} \mathrm{C}$. On the other hand, when we sintered in neon (which was used because it had the lowest $\mathrm{O}_{2} / \mathrm{H}_{2} \mathrm{O}$ impurities of gas available to us), we obtained the reasonably sized grains as the sintering rate and the grain growth of $\mathrm{UO}_{2+\mathrm{x}}$ is much higher at lower temperatures than is the case for stoichiometric $\mathrm{UO}_{2}$. However, for some reason the pellets did not remain intact when sintered in a non-reducing atmosphere. This will be investigated further in the future. 


\section{3. $\mathrm{H}_{2} \mathrm{O}_{2}$ measurement}

Near-surface hydrogen peroxide $\left(\mathrm{H}_{2} \mathrm{O}_{2}\right)$ concentration is an important variable that can impact the stability of used fuel as a waste form in a repository environment (Sunder et al. 1997). The purpose of the spectroscopic measurements described here was to determine if ultra-violet-visible light (UV-Vis) methods can be used for measuring low solution concentrations of $\mathrm{H}_{2} \mathrm{O}_{2}$ predicted by radiolytic models (e.g., $10^{-6}$ to $10^{-7} \mathrm{M}$ ). The ultimate goal was to choose an indicator with the lowest detection limit and greatest stability when complexed with peroxide for use in radiolytic studies to measure the accumulation of $\mathrm{H}_{2} \mathrm{O}_{2}$ in solution with time. These results will then be compared with the radiolytic models for $\mathrm{H}_{2} \mathrm{O}_{2}$ generation developed as part of the UFD program (Buck et al., 2012).

Three different hydrogen peroxide indicators were chosen for the scoping study: vanadium, titanium, and methylene blue. The first two indicators are "direct" where a bond is formed between the peroxide and the metal compound in a primary reaction; the latter requires an additional step where $\mathrm{H}_{2} \mathrm{O}_{2}$ liberates iodine, which then complexes with the methylene blue. Since colored solutions are needed for UV-Vis analysis, each indicator was tested for its reaction with hydrogen peroxide solutions of decreasing concentrations. First, three series of samples with $\mathrm{H}_{2} \mathrm{O}_{2}$ concentrations ranging from $0.1 \mathrm{M}$ to $1 \times 10^{-7} \mathrm{M}$ were generated in decadal increments. To each series, a different indicator was added. For V, a 1:1 ratio of $\mathrm{H}_{2} \mathrm{O}_{2}$ solution was mixed with $0.5 \mathrm{~g}$ of $\mathrm{Na}_{3} \mathrm{VO}_{4} \cdot 16 \mathrm{H}_{2} \mathrm{O}$ dissolved in $30 \mathrm{~mL}$ of water. For Ti, $\mathrm{Ti}(\mathrm{III}) \mathrm{Cl}_{3}$ was boiled in sulfuric acid to form $\mathrm{Ti}(\mathrm{IV}) \mathrm{OSO}_{4}$ in solution. This solution was centrifuged to isolate solid white precipitate from the clear solution, and $2 \mathrm{~mL}$ of clear indicator solution was added to $2 \mathrm{~mL}$ of each $\mathrm{H}_{2} \mathrm{O}_{2}$ concentration in the series. Finally, the method of Sunil and Narayana (2008) was used for testing the methylene blue indicator.

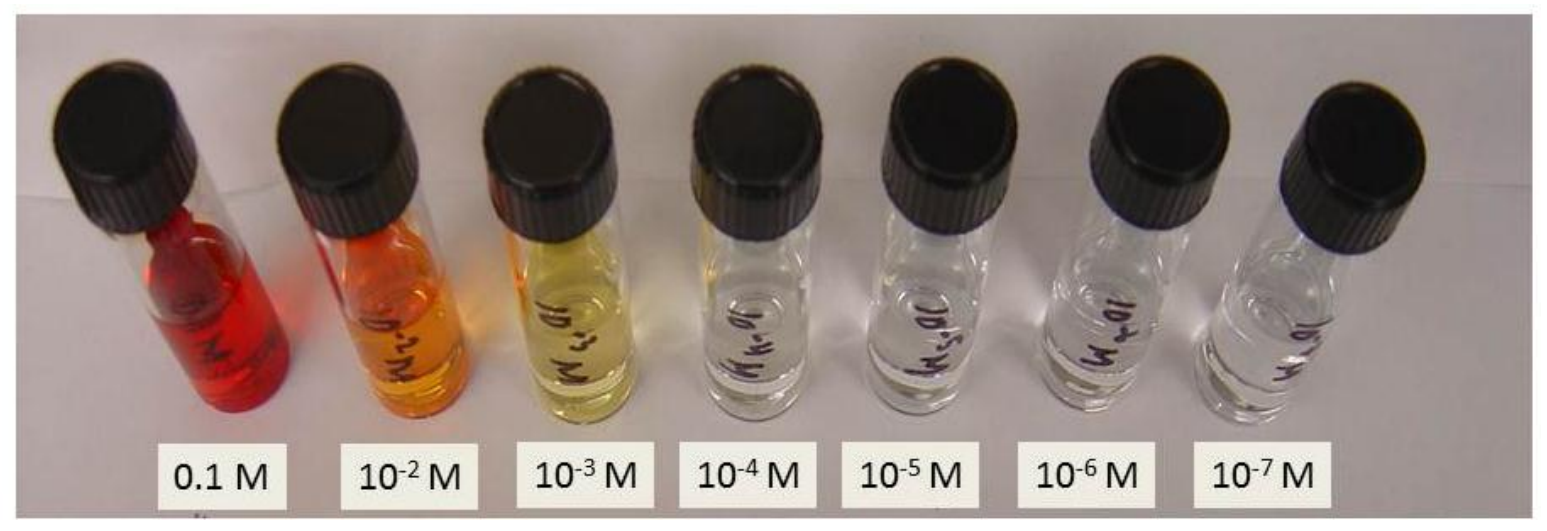

Figure 3.1 Photograph of a series of $\mathrm{H}_{2} \mathrm{O}_{2}$ concentrations using $\mathrm{Ti}(\mathrm{IV}) \mathrm{OSO}_{4}$ as the indicator. 
Spectroscopy Results. For UV-Vis analysis, 13 samples with smaller $\mathrm{H}_{2} \mathrm{O}_{2}$ concentration increments were generated for measurement in the $10^{-4}$ to $10^{-7} \mathrm{M}$ range. Results from the Ti(IV) series are shown in Figure 3.2. Using a $1 \mathrm{~cm}$ path-length plastic cuvette on a 400 -series charge-coupled device array spectrophotometer (Spectral Instruments Inc.) with a 200- to 950-nm scanning range, absorbance peaks were detected in the low $400 \mathrm{~nm}$ range at a minimum $\mathrm{H}_{2} \mathrm{O}_{2}$ concentration of $7 \times 10^{-6} \mathrm{M}$. Absorption peak intensity increases with increasing peroxide concentration as shown by the calibration plots in Figure 3.3. These data suggest that the Ti(IV) indicator method can produce reliable results with UV-Vis spectroscopy analysis and would be a good candidate for the longer path length set-up to push the detection limit into the $10^{-7} \mathrm{M}$ range.

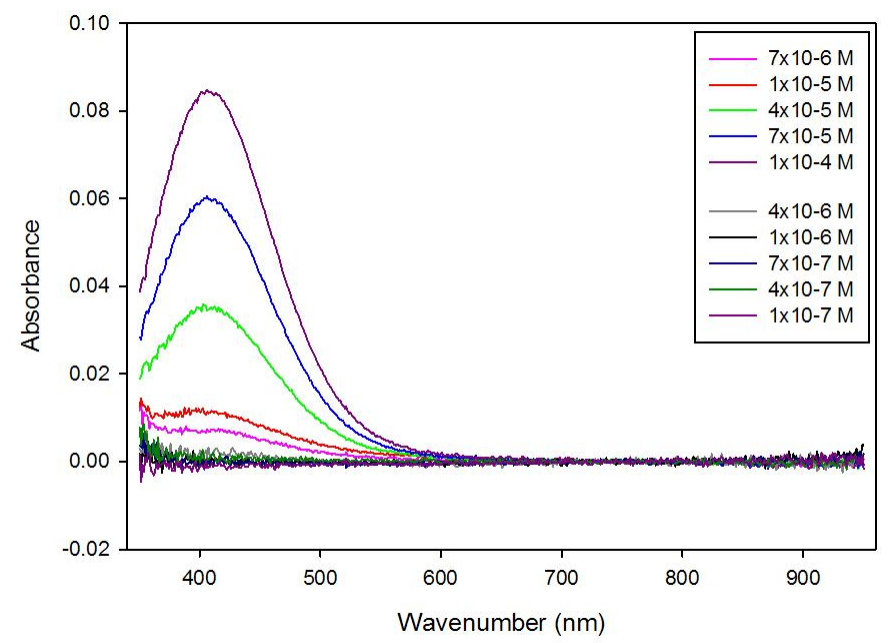

Figure 3.2 Short path length UV-Vis spectra for $\mathrm{H}_{2} \mathrm{O}_{2}+\mathrm{Ti}(\mathrm{IV}) \mathrm{OSO}_{4}$ as indicator showing detection upwards of $7 \times 10^{-6} \mathrm{M}$ (background subtracted).

Figure 3.3 shows a calibration plot with the titanium-based indicator. This species appeared to the best suited for low-level detection of peroxide. 

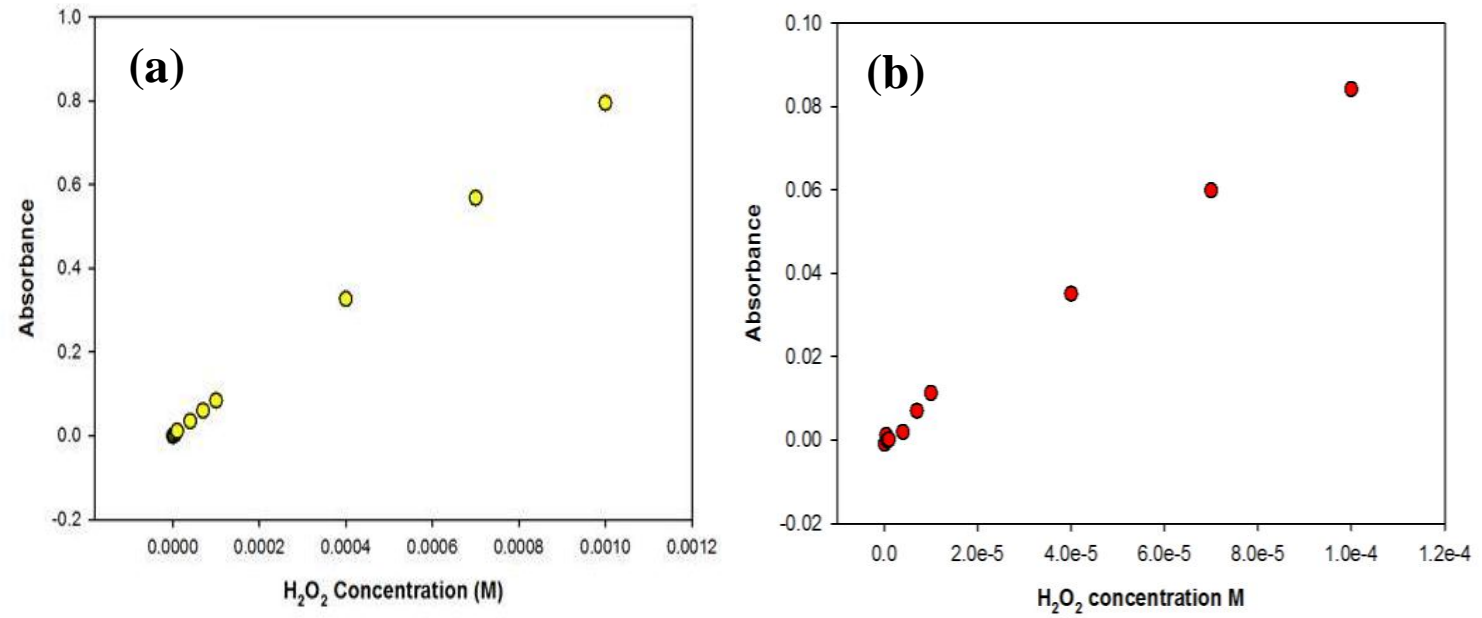

Figure 3.3 Calibration plot for the detection of $\mathrm{H}_{2} \mathrm{O}_{2}$ with Ti(IV)OSO $\mathrm{O}_{4}$ indicator: (a) $1 \times 10^{-7} \mathrm{M}$ to $1 \times 10^{-3}$ $\mathrm{M}$ and (b) $1 \times 10^{-4}$ and lower

Next, the methylene blue samples were tested using the same set-up. Absorbance peaks were present in the 600-700 nm wavelength range; however, peak intensity did not increase consistently with increasing $\mathrm{H}_{2} \mathrm{O}_{2}$ concentration and instead fluctuated without an identifiable pattern (see Figure 3.4). As a result, a reliable calibration plot could not be generated. Further tests were performed using a fresh methylene blue-like stock material (toluidene blue), but the same purple precipitate formed. One final test was performed to see if the yellow solution color generated by the liberation of iodine by hydrogen peroxide could be used as a spectroscopic signal; however, the same fluctuation in signal intensity occurred as in the previous studies. Despite promising detection limits stated in the literature of $10^{-7} \mathrm{M} \mathrm{H}_{2} \mathrm{O}_{2}$ (Sunil and Narayana, 2008) and shown in Figure 3.4, this indicator method was abandoned due to experimental inconsistencies. 


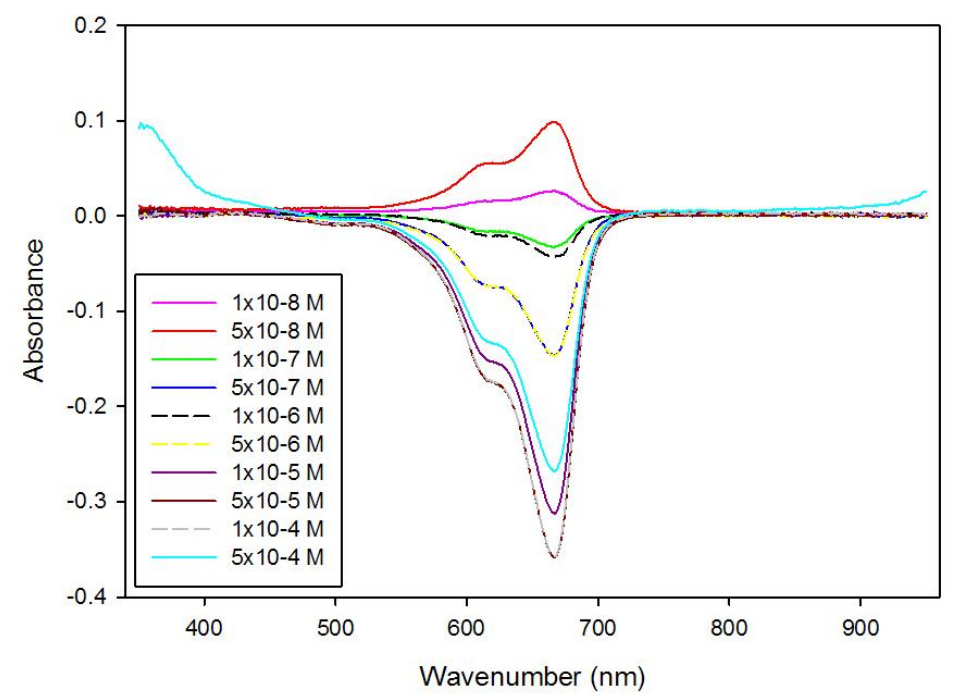

Figure 3.4 Averaged UV-Vis data for methylene blue indicator.

Long Path-Length Study. Given the success of the Ti(IV) indicator, a long path-length study was attempted using an encased 5 meter $(\mathrm{m})$ solution line on the same UV-Vis system. In an attempt to quantify Ti(IV) concentration in solution, a fresh batch of Ti(IV) indicator solution was generated; however, it had more white film than the previous Ti(IV) solution. Even though a syringe filter was used to introduce the Ti(IV) indicator to the $\mathrm{H}_{2} \mathrm{O}_{2}$ samples with different concentrations, samples became cloudy. Upon comparing the lowest-detected $7 \times 10^{-6} \mathrm{M}$ absorbance peak to the original $7 \times 10^{-6} \mathrm{M} \mathrm{H}_{2} \mathrm{O}_{2}+$ Ti(IV) solution, a shift in peak position to slightly longer wavelengths was observed. This shift is attributed to the difference in indicator solutions (perhaps hydrolysis of the Ti(IV) complex in solution) and instead a sub-set of the original $\mathrm{Ti}(\mathrm{IV}) \mathrm{H}_{2} \mathrm{O}_{2}$ samples were used to avoid complications in this analysis. The significance of this comparison is that the Ti(IV) peroxide complexes generated 2 months prior were found to be present and stable in solution still (see Figure 3.5). 


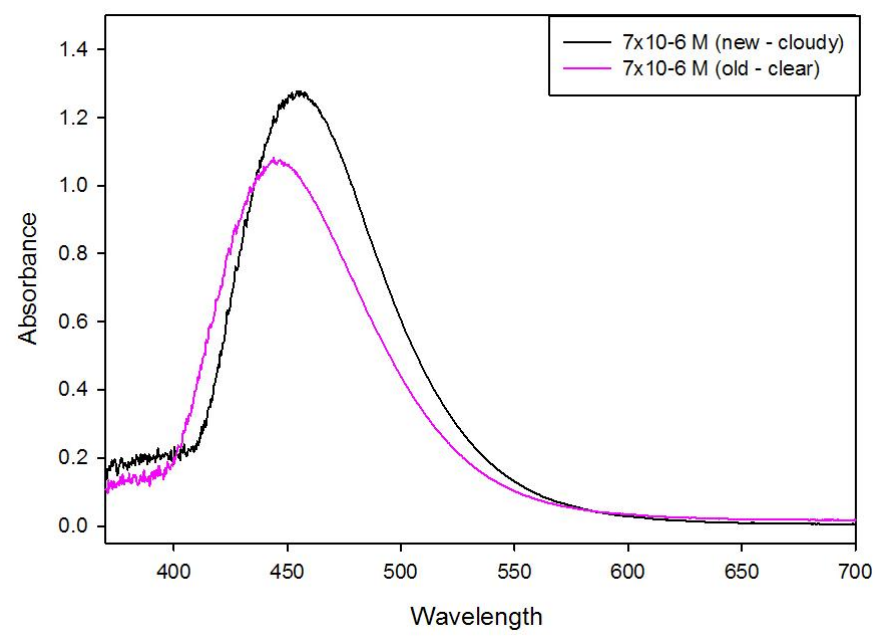

Figure 3.5 Comparison of new and old peroxide samples with different batches of $\mathrm{Ti}(\mathrm{IV}) \mathrm{OSO}_{4}$ as the indicator.

To test the detection limit of the long path-length system, samples with $\mathrm{H}_{2} \mathrm{O}_{2}$ concentrations of $7 \times 10^{-6} \mathrm{M}$, $4 \times 10^{-6} \mathrm{M}$, and $1 \times 10^{-6} \mathrm{M}$ were chosen for analysis. In Figure 3.6, no apparent signal was detected at the lowest limit. However, when the original $1 \times 10^{-4} \mathrm{M}$ Ti(IV)-peroxide solution was diluted to a concentration of $1 \times 10^{-7} \mathrm{M}$, an absorbance peak was visible (see Figure 3.6). This result indicates that the long path-length method will be able to provide detection limites in the $10^{-6}$ to $10^{-7} \mathrm{M}$ range needed for the radiolytic study. The added benefit of the Ti(IV) indicator method is that the Ti-peroxide is stable over weeks to months.

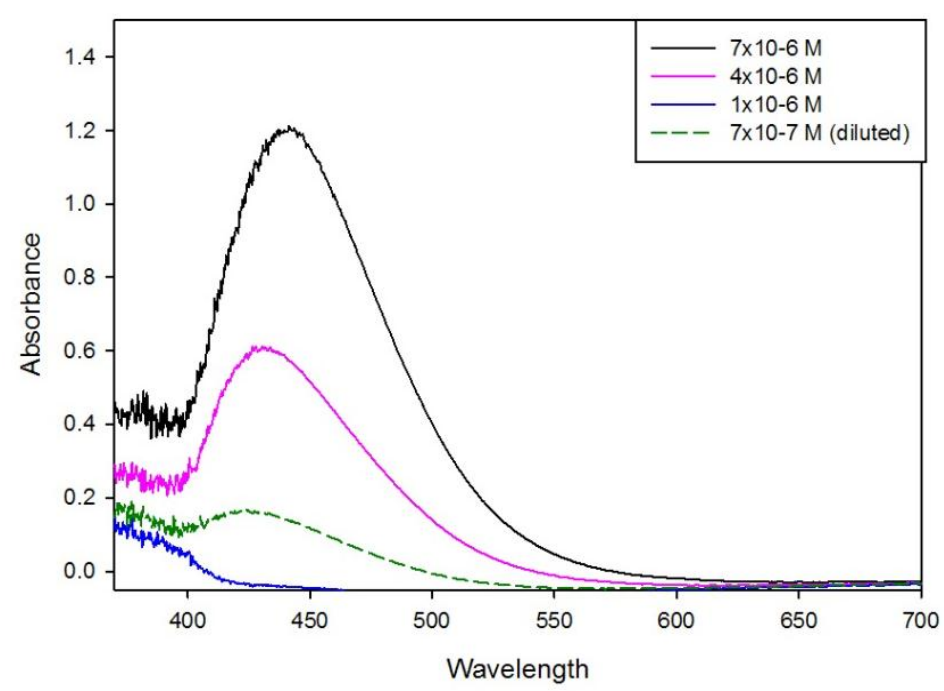

Figure 3.6 Long path-length $\mathrm{UV}-\mathrm{V}$ is for $\mathrm{H}_{2} \mathrm{O}_{2}+\mathrm{Ti}(\mathrm{IV}) \mathrm{OSO}_{4}$ as indicator. 
The next steps will be to finalize designs of a radiolytic test to measure $\mathrm{H}_{2} \mathrm{O}_{2}$ concentrations as a function of time in the presence of an alpha radiation source. Ti(IV) will be used as the indicator for peroxide generated in this system. Results will ultimately be compared with radiolytic models being developed in another part of this study.

\section{Conclusions}

The methodology for producing SimFuels suitable for testing has been established. Reasonably large sized grains can be generated that will be used in UNF testing.

Using the $\mathrm{Ti}(\mathrm{IV}) \mathrm{OSO}_{4}$ indicator and the long-path length detector we have developed a method for accurately analyzing low concentrations of $\mathrm{H}_{2} \mathrm{O}_{2}$ in solution. This was an important step in developing the testing program to validate the radiolysis model. 


\section{References}

Ainscough, J. B., F. Rigby, and S. C. Osborn, 1974. The effect of titania on grain growth and densification of sintered $\mathrm{UO}_{2}$, Journal of Nuclear Materials 52: 191-203.

Buck, E. C., R. S. Wittman, F. N. Skomurski, K. J. Cantrell, B. K. McNamara, and C. Z. Soderquist, 2012. Radiolysis Process Modeling Results for Scenarios, FCRD-UFD-2012-000199, Pacific Northwest National Laboratory Report, PNNL-21554, Richland, WA.

Carbol, P., P. Fors, T, Gouder, and K. Spahiu, 2009. Hydrogen suppresses $\mathrm{UO}_{2}$ corrosion. Geochimica et Cosmochimica Acta, 73: 4366-4375.

Harada, Y. 1996. Sintering behavior of niobia-doped large grain $\mathrm{UO}_{2}$ pellet, Journal of Nuclear Materials 238: $237-243$.

Kim, S. H., and C. Y. Joung, et al. 2002. Density decrease of oxidatively sintered $\mathrm{UO}_{2}-5 \mathrm{wt} \% \mathrm{CeO}_{2}$ pellets during resintering in $\mathrm{H}_{2}$ atmosphere. Journal of Nuclear Materials 302: 227-231.

Kleykamp, H. 1985. The chemical state of the fission products in oxides fuels, Journal of Nuclear Materials 131: 221-246.

Kutty, T. R., P. V. Hegde, et al. 2002. Densification behavior of $\mathrm{UO}_{2}$ in six different atmospheres. Journal of Nuclear Materials 305: 159-168.

Pastina, B., and J. A. LaVerne, 2001. Effect of molecular hydrogen on hydrogen peroxide in water radiolysis, Journal of Physics and Chemistry, B105: 9316-9322.

Ray, I. L. F., Hj. Matzke, H. A. Thiele, and M. Kinoshita, 1997. An Electron Microscopy Study of the RIM Structure of a $\mathrm{UO}_{2}$ Fuel with a High Burnup of 7.9\% FIMA, Journal of Nuclear Materials 245: 115123.

Roth, O., and J. A. LaVerne, 2011. Effect of $\mathrm{pH}$ on $\mathrm{H}_{2} \mathrm{O}_{2}$ production in the radiolysis of water, Journal of Physics and Chemistry, A115: 700-708.

Stroes-Gascoyne, S., F. Garisto, and J.S. Betteridge. 2005. The effects of alpha-radiolysis on $\mathrm{UO}_{2}$ dissolution determined from batch experiments with ${ }^{238} \mathrm{Pu}$-doped $\mathrm{UO}_{2}$. Journal of Nuclear Materials 346 : $5-15$. 
Shannon, R. D., 1976. Revised effective ionic radii and systematic studies of interatomic distances in halides and chalcogenides, Acta. Cryst. A32: 751-767.

Spino, J., and D. Papaioannou, 2000. Lattice Parameter Changes associated with the Rim-Structure Formation in High Burnup $\mathrm{UO}_{2}$ Fuels by Micro X-Ray Diffraction, Journal of Nuclear Materials 281: 146-162.

Sunder, S., D.W. Shoesmith, and N.H. Miller. 1997. Oxidation and dissolution of nuclear fuel $\left(\mathrm{UO}_{2}\right)$ by the products of the alpha radiolysis of water. Journal of Nuclear Materials 244: 66-74.

Sunil, K., and B. Narayana, 2008. Spectrophotometric determination of hydrogen peroxide in water and cream samples. Bull. Environ. Contam. Toxicol., 81: 422-426.

Thomas, L. E., R. E. Einziger, and H. C. Buchanan, 1993. Effect of Fission Products on Air-Oxidation of LWR Spent Fuel, Journal of Nuclear Materials 201: 310-319.

Une, K., and M. Oguma, 1988. Thermodynamic properties of nonstoichiometric urania-gadolina solid solutions in the temperature range $700^{\circ}-1100^{\circ} \mathrm{C}$, Journal of Nuclear Materials 110: 215-222.

Vollath, D., H. Elbel, et al. 1982a. Development of the structure during reduction sintering of $\mathrm{UO}_{2}-\mathrm{PuO}_{2}$ pellets from granulated powders. Journal of Nuclear Materials 106: 181-189.

Vollath, D., H. Wedemeyer, et al. 1982b. Influence of process parameters on the fabrication of $\mathrm{UO}_{2}-\mathrm{PuO}_{2}$ pellets using the granulation technique. Journal of Nuclear Materials 106: 191-197.

Willis, B. T. M., 1978. The defect structure of hyper-stoichiometric uranium dioxide, Acta Cryst. A34: 88-90. 


\section{ACKNOWLEDGEMENTS}

The work summarized in this report was conducted at Pacific Northwest National Laboratory.

Programmatic guidance provided by D. Sassani (Sandia National Laboratory) and J. Buelt (PNNL) is also gratefully acknowledged. 